\title{
Maturation, morphological, motor and technical characteristics of under 16 female track and field athletes
}

\section{Características maturacionais, morfológicas, motoras e técnicas de atletas femininas sub 16 de atletismo}

\author{
Jefferson Verbena de Freitas ${ }^{2}$ \\ (D) https://orcid.org/0000-0002-0582-7950 \\ Francisco Zacaron Werneck ${ }^{3}$ \\ (D) https://orcid.org/0000-0003-1966-8820 \\ Renato Siqueira de Souza ${ }^{1}$ \\ (iD https://orcid.org/0000-0002-3846-4754 \\ Phelipe Henrique Cardoso de Castro \\ (D) https://orcid.org/0000-0002-0094-2511 \\ António José Figueiredo ${ }^{4}$ \\ (D) https://orcid.org/0000-0001-6956-0514 \\ Jorge Roberto Perrout de Lima ${ }^{1}$ \\ (D) https://orcid.org/0000-0003-0073-8673
}

Abstract - There is growing interest in identifying morphological, motor, maturation characteristics, as well as their changes, of children and adolescents in systematized training in various sports. Knowledge of these characteristics is important for coaches and researchers because they provide parameters for assessing youth development during training. For track and field, studies on the category under 16 are scarce. Thus, the objectives of this study are to describe the profile and to design a percentile table of morphological, motor, maturation and eventspecific variables of under 16 athletes. 105 young athletes were evaluated on two consecutive days. On the first day, an anamnesis of athletes and coaches was performed. Anthropometric and anaerobic measurements were analyzed in shot put, long jump, $800 \mathrm{~m}$ run. On the second day, flexibility, vertical impulse, upper limb strength, speed and maximal aerobic speed were evaluated. The biological maturation was evaluated by the percentage of the predicted adulte height. A table with percentiles was prepared with the data of all athletes. Another table with the results of the whole group plus mean and standard deviation was prepared. A last table was prepared containing data divided by group of sports events. The morphological variables presented differences between the groups as to body mass, BMI and sum of skinfolds. Significant differences were observed only for the motor variable MAS. No significant differences were observed only for long jump. When divided by groups, it was evident that throwers are different from the other athletes in some morphologic variables and in specific sports events.

Key words: Athletics; Characteristics; Track and field.

Resumo - É crescente o interesse em identificar caracteristicas morfológicas, motoras e maturacionais, bem como suas modificaçôes em crianças e adolescentes inseridos em treinamentos sistematizados nas mais variadas modalidades esportivas. O conhecimento dessas características é importante para que treinadores e pesquisadores tenham parâmetros de avaliação do desenvolvimento do jovem durante o treinamento. Para o atletismo, são limitados estudos para a categoria sub 16. Desta forma, os objetivos são, descrever o perfil e elaborar uma tabela de percentil das variáveis morfológicas, motoras, maturacionais e de provas especificas de atletas sub 16. Foram avaliadas 105 jovens atletas em dois dias consecutivos. No primeiro dia, foi realizada a anamnese nos atletas e treinadores, medidas antropométricas, anaeróbicas e as provas do arremesso de peso, salto em distância, corrida de $800 \mathrm{~m}$. No segundo dia, foi avaliada a flexibilidade, impulsão vertical, força de membro superior, velocidade e velocidade aeróbia máxima. A maturação biológica foi avaliada pelo percentual da estatura adulta predita. Foram elaboradas uma tabela de percentis com resultado de todas as atletas, outra com média e desvio padrão com os resultados do grupo todo e uma última dividida por grupo de provas. Nas variáveis morfológicas foram encontradas diferenças entres os grupos para a massa corporal, IMC e somatório de dobras, nas motoras apenas na VMA e nas provas especificas não foi observada diferença significativa apenas salto em distância. Quando dividido pelos grupos, se evidenciou que as lançadoras são diferentes das demais atletas em algumas variáveis moforlógicas e nas provas específicas.

Palavras-chave: Atletas; Atletismo; Características.
1 Universidade Federal de Juiz de Fora. Juiz de Fora, MG. Brasil.

2 Universidade Federal de Viçosa. Viçosa, MG. Brasil.

3 Universidade Federal de Ouro Preto. Ouro Preto, MG. Brasil.

4 Universidade de Coimbra. Portugal.

Received: 21 0ctober 2019 Accepted: 08 January 2020

How to cite this article Freitas JV, Werneck FZ, Souza RS, Castro PHC, Figueiredo AJ, Lima JRP. Maturation, morphological, motor and technical characteristics of under 16 female track and field athletes. Rev Bras Cineantropom Desempenho Hum 2020, 22:e68128. D0l: http://dx.doi. org/10.1590/1980-0037.2020v22e68128

Copyright: This work is licensed under a Creative Commons Attribution 4.0 International License. 


\section{INTRODUCTION}

According to the International Association of Athletic Federations (IAAF), the events of this sport, which result directly from the original motor patterns of running, jumping and throwing, are the oldest competitions of humanity. Success in such diverse events is determined by a diverse set of morphological and motor characteristics such as height, limb length, strength, aerobic capacity, power and speed articulated with specific technical aspects of each event ${ }^{1}$.

The training of track and field athletes is organized into a long-term training process that initially involves the selection of talents followed by a continuous monitoring of biological maturation, physical growth and physiological and motor adaptations in response to the training provided ${ }^{2}$. It is recommended that younger athletes devote more time to general training without defining in which competition they will compete, and progressively increase the proportion of specific training up to specialization in a main event.

The category under 16 , in which young people aged $13-15$ can participate, is the first category for which official competitions are held. In this age group, the greatest biological transformations occur due to the maturation process. Girls reach the peak of growth speed at around eleven years of age ${ }^{3}$, so that, in this category, athletes should already be close to their predicted adult stature and adult body size. Training at this time has become more structured, and incorporates a significant percentage of specific exercises. Young athletes do not yet have a specialization in a defined sports event, but can already be organized into speed, jumping, throwing and endurance groups according to their technical skills.

In order to monitor the athletes' development, coaches should identify performance-determining characteristics for each sport, and then select events capable of assessing these characteristics. Based on objective test data, they can select talents, monitor development, identify strengths and weaknesses, evaluate interventions, and prescribe training ${ }^{4}$ suggested that a testing battery be designed taking into account the characteristics of each sport. Thus, athletes of different modalities should be evaluated by specific tests. The results should be compared with reference values for each of such sports activities.

In the United States, for example, athletics is the most practiced sport by girls ${ }^{5}$. In Brazil, according to the Brazilian Athletics Confederation CBAT, there are 9,553 athletes with valid records. Of these, 2,509 are in the category under 16, and 1,077 are female. In the literature, there are testing batteries for training categories for some sports such as basketball and soccer. For track and field, even if it is a sport widely practiced by young people, no Brazilian studies were found reporting reference values for young athletes.

As the category under 16 is the beginning of the structuring of training towards specialization, it is unclear how specific the testing battery should 
be applied in order to monitor the development of athletes of this age group. Therefore, the objectives of this study are to describe the characteristics of under 16 female athletes by means of tables comprising maturation, morphological, motor and technical skills characteristics, and to observe if the classification of the results should be done globally or by group of sports.

\section{METHOD}

\section{Subjects}

105 under 16 female athletes (13-15 years old), belonging to nine CBAt affiliated teams and regular participants of official competitions of track and field, were evaluated. To participate in the study, all young women had to be engaged in track and field training for at least six months, and not report any type of injury at this time.

After presenting the study proposal to the athletes, coaches and parents, all were informed of the possible risks involved in the process. The girls and their guardians signed an informed consent authorizing the voluntary participation in the study. The Research Ethics Committee of the Federal University of Juiz de Fora approved this study under protocol number 566,839.

\section{Procedures}

The study was conducted on two consecutive days. Before any procedure, the volunteers should have remained 24 hours without physical exercises. The evaluation was conducted through morphological and maturation measurements, questionnaires to athletes, coaches and parents, and physical tests to evaluate the motor characteristics important for athletics: speed, anaerobic capacity, flexibility, vertical thrust, upper limb strength, aerobic power, in addition to practicing shot put, long jump, and 60 and $800 \mathrm{~m}$ runs.

On the first day, anamnesis, anthropometry, the Running-Based Anaerobic Sprint Test (RAST), shot put, long jump and $800 \mathrm{~m}$ run were performed. On the second day, the following tests were applied: sit-andreach, vertical jump, $60 \mathrm{~m}$ run, medicine ball throw and Léger-Boucher test.

- Questionnaire for Athletes - The athletes answered questions regarding age, track and field training time, participation and results in official competitions.

- Questionnaire for the Coach - The coaches indicated the best event for each athlete in the category under 16 . This information was used to allocate the athletes into event groups.

- Questionnaire for the Parents - The biological parents were sent a questionnaire to report their respective statures. This information was used to calculate the predicted adult height percentage as an indicator of biological maturation.

- Anthropometry - Anthropometric measurements were performed according to the standardization of the International Society for the 
Advancement of Kinanthropometry ${ }^{6}$. The following were measured: body mass, height, wingspan, sitting height and subscapular, supra iliac, triceps and leg skinfolds. Body mass index (BMI), length of lower limbs, and sum of skinfold thickness were calculated.

- Running-Based Anaerobic Sprint Test ${ }^{7}$ - Six 35 m runs were performed, with $10 \mathrm{~s}$ of passive interval between them. A Cefise photocell electronic timing equipment was used. All race times were recorded (T1, T2, T3, T4, T5 and T6). The percentage fatigue index (([longer time - shortest time] / shortest time) x 100) was calculated as an anaerobic capacity indicator.

- Sit-and-Reach $\mathrm{Test}^{8}$ - Three attempts were made, maintaining the distance reached for approximately three seconds. The greatest measurement was recorded as an indicator of flexibility.

- Vertical Impulse Test ${ }^{9}$ - With regard to vertical impulse, it was decided to choose two tests, the squat jump and a test with counter-movement, to assess any contribution of the static and elastic muscle component. A Cefise contact mat, Jump System Pro, and the analysis software JumpSystem version 1.0.2.9 were used. Three attempts with $10 \mathrm{~s}$ of squat jump interval were made and, after one minute of interval, three attempts with $10 \mathrm{~s}$ of counter-movement jump interval were performed. The best attempt for each type of jump was recorded as an indicator of lower limb strength.

- Medicine ball throw $(2 \mathrm{~kg})^{10}$-Three attempts were made, and the largest distance reached was recorded as an indicator of upper limb strength.

- Legér-Boucher Test ${ }^{11}$ - Progressive test in a track and field track at a $9 \mathrm{~km} / \mathrm{h}$ starting speed, with increments of $1 \mathrm{~km} / \mathrm{h}$ every two minutes. The run speed was controlled by audible signals and cones positioned every $50 \mathrm{~m}$. The test was interrupted with voluntary exhaustion or when athletes could not reach at least $2 \mathrm{~m}$ from the cone twice in a row. The velocity of the last completed stage and the time elapsed at the unfinished stage were recorded ${ }^{12}$, and the following equation was applied: VMA $(\mathrm{km} / \mathrm{h})=($ speed of the last completed stage + (time in seconds of the incomplete stage / 120) as an indicator of the maximum aerobic speed.

- Percentage of Predicted Adult Height - Calculated according to the procedures proposed by Khamis and Roche ${ }^{13}$. The predicted adult height was estimated by the equation (intercept + height * (coefficient for height $)+$ body mass * (coefficient for body mass) + parental mean height * (coefficient for parental average height). The percentage of predicted adult age was calculated by the equation (current height / predicted height) *100), which is an indicator of biological maturation.

- Shot put $(3 \mathrm{~kg}$ ) and Long Jump - Each athlete had three attempts following the official rules. Between each attempt, a five minute interval was performed. The best mark achieved in each event was recorded with specific performance indicators of track and field.

- 800 meters - Each athlete traveled the distance in the shortest time 
possible. The race was performed with a maximum of five athletes at a time. The time obtained was used as an indicator of specific performance of track and field.

- 60 meters - two trials were performed and the times were measured by a Cefise photocell electronic timing equipment. The shortest time obtained was used as an indicator of specific performance of track and field.

\section{Statistical Treatment}

The characterization of the athletes' profile was performed using descriptive statistics by calculating means, standard deviation, minimum and maximum values, and position measurements (percentiles). The parametric assumptions of normality and equality of variance were tested by the Kolmogorov-Smirnov test and the Levene test, respectively. To test for differences between event groups, the ANOVA was applied and, when significant differences were detected, a Tukey post-hoc test was performed. All analyses were performed using the SPSS software (v.22, SPSS Inc., Chicago, IL, USA) at a significance level of $5 \%(\mathrm{p} \leq 0.05)$.

\section{RESULTS}

Table 1 shows the characteristics of athletes under 16 in terms of maturation, morphology, motor performance, and performance in specific track and field events.

Table 2 shows the percentile values of variables that characterize under 16 athletes in terms of maturity, morphology, motor performance, and performance in specific events.

In Table 3, the athletes were divided into groups of throw, jump, endurance and speed. Regarding morphological variables, the throw group presented significantly higher body mass, BMI and skinfold sum than the other groups. Regarding the motor variables, the endurance group presented values of maximum aerobic speed equal to the speed group and higher than the throw and jump groups. The specific performance of the throw group is lower than the speed group in the $60 \mathrm{~m}$ run and than the endurance group in the $800 \mathrm{~m}$ run, and higher than the other groups in the shot put group.

\section{DISCUSSION}

This study was conducted in the context of long-term training according to the understanding that assessment is an important tool for talent selection and for monitoring progress due to biological maturation and in response to the training. As there were no tables containing reference values for the classification of event results usually applied to young track and field athletes, one of the objectives of this study was to design adequate tables for the evaluation of under 16 female track and field athletes.

The category under 16 includes athletes from 13 to 15 years old, which 
Table 1. Maturation, anthropometric, motor and performance-specific characteristics of young under 16 female athletes $(n=105)$.

\begin{tabular}{|c|c|c|c|c|}
\hline Characterístics & Minimum & Maximum & Average & DP \\
\hline Age (years) & 13.0 & 15.8 & 14.0 & 0.9 \\
\hline Pratice Time (months) & 6.0 & 84.0 & 21.9 & 10.9 \\
\hline \multicolumn{5}{|l|}{ Maturation } \\
\hline Predicted Adult Stature (cm) & 151.1 & 183.4 & 162.9 & 5.8 \\
\hline Percentage of Predicted Adult Height (\%) & 90.1 & 99.9 & 96.8 & 2.2 \\
\hline \multicolumn{5}{|l|}{ Morphological } \\
\hline Body Mass (kg) & 33.1 & 73.8 & 48.4 & 7.6 \\
\hline Height (cm) & 142.5 & 183.0 & 157.7 & 7.2 \\
\hline Body Mass Index $\left(\mathrm{kg} / \mathrm{m}^{2}\right)$ & 14.3 & 26.8 & 19.4 & 2.3 \\
\hline Length of Lower Limbs (cm) & 67.5 & 92.0 & 76.0 & 5.0 \\
\hline Sitting Height $(\mathrm{cm})$ & 73.5 & 91.0 & 81.7 & 3.6 \\
\hline Wingspan $(\mathrm{cm})$ & 138.0 & 190.0 & 162.4 & 9.9 \\
\hline Sum of Skinfold Thickness (mm) & 23.1 & 84.5 & 41.9 & 11.7 \\
\hline \multicolumn{5}{|l|}{ Motor } \\
\hline Sit-and-Reach Test (cm) & 16.0 & 50.0 & 34.4 & 6.9 \\
\hline Maximum Aerobic Speed (km/h) & 9.1 & 16.5 & 12.2 & 1.4 \\
\hline Squat Jump (cm) & 14.1 & 39.0 & 26.2 & 5.2 \\
\hline Counter-movement Jump (cm) & 6.4 & 49.1 & 27.9 & 6.1 \\
\hline Medicine Ball Throw (m) & 2.3 & 5.3 & 3.6 & 0.6 \\
\hline Fatigue Index RAST (\%) & 6.8 & 58.4 & 19.0 & 7.3 \\
\hline \multicolumn{5}{|l|}{ Technical } \\
\hline $60 \mathrm{~m}(\mathrm{~s})$ & 7.9 & 12.7 & 9.4 & 0.8 \\
\hline Shot Put (m) & 3.1 & 9.4 & 5.7 & 1.4 \\
\hline Long Jump (m) & 1.7 & 4.9 & 3.5 & 0.6 \\
\hline $800 \mathrm{~m}(\mathrm{~s})$ & 155.0 & 311.0 & 223.9 & 38.3 \\
\hline
\end{tabular}

Note. Sum of skinfolds: triceps, suprailiac, subscapularis and leg.

Table 2. Percentile values of maturation, morphological, motor and specific tests of under 16 female athletes $(n=105)$.

\begin{tabular}{|lccccccccccc}
\hline Characterístics & P10 & P20 & P25 & P30 & P40 & P50 & P60 & P70 & P75 & P80 & P90 \\
\hline Maturation & & & & & & & & & & & \\
\hline Predicted Adult Stature (cm) & 154.9 & 158.0 & 158.9 & 159.7 & 161.6 & 163.4 & 164.3 & 165.9 & 166.6 & 167.4 & 170.1 \\
\hline Percentage of Predicted Adult Height (\%) & 93.4 & 94.7 & 95.3 & 96.1 & 96.7 & 97.3 & 97.9 & 98.2 & 98.3 & 98.7 & 99.3 \\
\hline Morphological & & & & & & & & & & & \\
\hline Body Mass (kg) & 39.8 & 41.8 & 42.8 & 43.8 & 45.0 & 46.9 & 49.1 & 52.1 & 53.3 & 54.8 & 59.0 \\
\hline Height (cm) & 148.8 & 151.0 & 152.5 & 153.8 & 155.2 & 158.0 & 159.5 & 161.0 & 161.9 & 162.4 & 167.3 \\
\hline Body Mass Index (kg/m²) & 17.1 & 17.7 & 17.9 & 18.0 & 18.4 & 18.9 & 19.4 & 20.1 & 20.6 & 21.2 & 22.6 \\
\hline Length of Lower Limbs (cm) & 69.4 & 71.5 & 72.4 & 73.0 & 74.5 & 75.7 & 77.0 & 78.2 & 79.5 & 80.0 & 82.7 \\
\hline Wingspan (cm) & 150.0 & 155.0 & 156.0 & 157.0 & 159.0 & 161.0 & 164.2 & 167.0 & 168.4 & 170.5 & 175.5 \\
\hline Sum of Skinfold Thickness (mm) ${ }^{*}$ & 58.4 & 52.1 & 50.7 & 47.2 & 47.2 & 40.1 & 37.4 & 34.2 & 33.0 & 31.7 & 28.8 \\
\hline Motor & & & & & & & & & & & \\
\hline Sit-and-Reach Test (cm) & 24.0 & 29.0 & 30.0 & 32.0 & 33.4 & 34.0 & 37.0 & 38.1 & 39.2 & 40.0 & 42.4 \\
\hline Maximum Aerobic Speed (km/h) & 10.5 & 11.1 & 11.1 & 11.4 & 11.6 & 12.1 & 12.5 & 13.1 & 13.1 & 13.3 & 14.0 \\
\hline Squat Jump (cm) & 19.7 & 22.3 & 22.7 & 23.6 & 24.3 & 25.5 & 26.6 & 29.9 & 29.7 & 30.4 & 33.9 \\
\hline Counter-movement Jump (cm) & 19.8 & 23.8 & 24.4 & 25.2 & 26.2 & 27.7 & 29.1 & 30.0 & 31.0 & 32.1 & 36.8 \\
\hline Medicine Ball Throw (m) & 2.8 & 3.0 & 3.1 & 3.2 & 3.4 & 3.6 & 3.8 & 3.8 & 4.0 & 4.1 & 4.4 \\
\hline Fatigue Index RAST (\%)* & 26.9 & 23.4 & 21.2 & 20.2 & 19.2 & 18.2 & 16.8 & 15.5 & 14.4 & 13.8 & 11.3 \\
\hline Technical & & & & & & & & & & \\
\hline 60 m (s) & 10.4 & 9.9 & 9.8 & 9.7 & 9.6 & 9.4 & 9.2 & 9.0 & 8.9 & 8.8 & 8.5 \\
\hline Shot Put (m) & 3.9 & 4.4 & 4.6 & 4.8 & 5.3 & 5.8 & 6.0 & 6.2 & 6.4 & 6.8 & 7.5 \\
\hline Long Jump (m) & 2.7 & 3.0 & 3.1 & 3.3 & 3.5 & 3.6 & 3.8 & 3.9 & 4.0 & 4.0 & 4.4 \\
\hline 800 m (s) ${ }^{*}$ & 284 & 259 & 250 & 244 & 228 & 220 & 206 & 198 & 195 & 190 & 175 \\
\hline
\end{tabular}

Note. Sum of skinfolds: triceps, suprailiac, subscapularis and leg; ${ }^{*}$ inverted percentile values. 
Table 3. Characteristics of maturation, morphological, motor and specific tests of under 16 female athletes by sports event groups ( $n=105)$.

\begin{tabular}{|c|c|c|c|c|c|}
\hline Characterístics & $\begin{array}{c}\text { Throwers } \\
(n=14)\end{array}$ & $\begin{array}{c}\text { Jumpers } \\
(\mathrm{n}=39)\end{array}$ & $\begin{array}{c}\text { Endurance } \\
n=11)\end{array}$ & $\begin{array}{c}\text { Sprinters } \\
(\mathrm{n}=41)\end{array}$ & $P$ \\
\hline Age (years) & $14.1 \pm 0.9$ & $13.7 \pm 0.9$ & $14.3 \pm 1.0$ & $14.2 \pm 0.8$ & 0.074 \\
\hline Pratice Time (months) & $19.8 \pm 12.8$ & $22.4 \pm 22.7$ & $32.1 \pm 29.7$ & $19.3 \pm 18.2$ & 0.336 \\
\hline \multicolumn{6}{|l|}{ Maturation } \\
\hline Predicted Adult Stature (cm) & $163.0 \pm 6.3$ & $164.6 \pm 5.6$ & $163.0 \pm 3.7$ & $161.3 \pm 5.9$ & 0.084 \\
\hline Percentage of Predicted Adult Height (\%) & $97.5 \pm 1.7$ & $96.2 \pm 2.5$ & $97.6 \pm 1.9$ & $96.9 \pm 1.8$ & 0.096 \\
\hline \multicolumn{6}{|l|}{ morphological } \\
\hline Body Mass (kg) & $55.1 \pm 9.1 \mathrm{SRV}$ & $47.1 \pm 7.4 \mathrm{~L}$ & $48.2 \pm 6.3 \mathrm{~L}$ & $47.1 \pm 6.5 \mathrm{~L}$ & 0.003 \\
\hline Height (cm) & $159.0 \pm 6.9$ & $158.3 \pm 7.8$ & $159.0 \pm 5.0$ & $156.3 \pm 7.0$ & 0.455 \\
\hline Body Mass Index (kg/m²) & $21.7 \pm 2.9$ SRV & $18.7 \pm 2.4 \mathrm{~L}$ & $19.4 \pm 1.6 \mathrm{~L}$ & $19.2 \pm 1.7 \mathrm{~L}$ & 0.000 \\
\hline Length of Lower Limbs (cm) & $75.5 \pm 5.6$ & $77.3 \pm 5.3$ & $76.9 \pm 4.0$ & $74.7 \pm 4.5$ & 0.118 \\
\hline Wingspan (cm) & $161.9 \pm 12.8$ & $164.3 \pm 9.6$ & $163.6 \pm 9.2$ & $160.8 \pm 9.2$ & 0.587 \\
\hline Sum of Skinfold Thickness (mm) & $51.1 \pm 12.2$ SRV & $41.3 \pm 12.0 \mathrm{~L}$ & $36.6 \pm 9.9 \mathrm{~L}$ & $40.7 \pm 10.3 \mathrm{~L}$ & 0.008 \\
\hline \multicolumn{6}{|l|}{ Motor } \\
\hline Sit-and-Reach Test (cm) & $34.9 \pm 6.3$ & $32.5 \pm 7.8$ & $34.7 \pm 5.5$ & $35.9 \pm 6.3$ & 0.164 \\
\hline Maximum Aerobic Speed (km/h) & $11.6 \pm 1.4 \mathrm{R}$ & $12.0 \pm 1.3 \mathrm{R}$ & $13.3 \pm 1.7 \mathrm{LS}$ & $12.2 \pm 1.2$ & 0.013 \\
\hline Squat Jump (cm) & $24.7 \pm 5.4$ & $25.1 \pm 5.2$ & $28.4 \pm 6.8$ & $27.2 \pm 4.5$ & 0.113 \\
\hline Counter-movement Jump (cm) & $27.6 \pm 6.5$ & $26.8 \pm 5.2$ & $31.0 \pm 5.5$ & $28.3 \pm 6.7$ & 0.220 \\
\hline Medicine Ball Throw (m) & $3.8 \pm 0.6$ & $3.4 \pm 0.6$ & $3.7 \pm 0.7$ & $3.7 \pm 0.6$ & 0.172 \\
\hline Fatigue Index RAST (\%) & $20.3 \pm 7.5$ & $18.2 \pm 5.2$ & $15.2 \pm 5.2$ & $20.4 \pm 8.9$ & 0.138 \\
\hline \multicolumn{6}{|l|}{ Technical } \\
\hline $60 \mathrm{~m}(\mathrm{~s})$ & $9.8 \pm 1.0 \mathrm{VR}$ & $9.6 \pm 0.8$ & $9.1 \pm 0.6 \mathrm{~L}$ & $9.2 \pm 0.7 \mathrm{~L}$ & 0,014 \\
\hline Shot Put (m) & $7.0 \pm 1.6$ VSR & $5.2 \pm 1.1 \mathrm{~L}$ & $6.2 \pm 1.8 \mathrm{~L}$ & $5.6 \pm 1.3 \mathrm{~L}$ & 0.000 \\
\hline Long Jump (m) & $34 \pm 0.6$ & $3.5 \pm 0.6$ & $3.6 \pm 0.9$ & $3.5 \pm 0.6$ & 0.937 \\
\hline $800 \mathrm{~m}(\mathrm{~s})$ & $244 \pm 46 R$ & $223 \pm 35$ & $196 \pm 34 \mathrm{~L}$ & $224 \pm 35$ & 0.019 \\
\hline
\end{tabular}

Note. Sum of skinfolds: triceps, suprailiac, subscapularis and leg; $L$ different in relation to throw; $S$ different in relation to jumps; $R$ different in relation to endurance; $V$ different in relation to speed

corresponds to the end of the peak speed of puberty growth. At the end of this period, the training begins to specialize with the progressive inclusion of specific elements of sports event groups (throws, jumps, speed and endurance), without, however, defining the athlete-specific event. In view of this circumstance, we also sought to observe if the athletes should be classified globally or by event group.

To ensure the specificity of the assessment, several tests were conducted to cover a broad set of physical and motor characteristics and techniques involved in the various track and field events, and 105 athletes from different teams from different Brazilian states of different competitive levels were evaluated. The athletes had been in systematic training for at least six months.

Biological maturation is described by Malina ${ }^{14}$ as a development process until the mature state is reached, enabling the organism to progress to higher levels of functioning. It varies according to the biological system of the person. It is generally observed in two contexts: "timing" and time. The "timing" refers to the occurrence of a particular maturation event (menarche, spermache, early breast development, appearance of pubic hair, and age of peak growth, among others). The time refers to the rate 
at which maturation progresses (the rate at which the transition from the early stage of sexual maturation to the mature stage occurs). In studies with young athletes, it is essential to control and verify the biological stage similarly to studies that seek to analyze whether there is a relationship between maturation and morphology and motor characteristics ${ }^{4,14}$. These studies show that children and young people who are maturely older may or may not show a better functional performance than late maturity ones depending on the variable analyzed. As reported in our results, there was no statistically significant difference between groups as for height or predicted adult height percentage. The results also evidence that all athletes are very close to the maximum values that could be reached. The subjects in our study have at this time on average $96.8 \pm 2.2 \%$ of their predicted adult height. This shows that they are all at the final process of the pubertal growth leap, so there is no difference in their maturation stage.

A consensus in the literature is that body dimensions are important for success in sports, and a good example of this is the characteristic morphotype of various sports. In our study, the group of throwers presented larger body dimensions (mass, BMI) than athletes in other groups. For jumpers, sprinters and endurance runners, the values were similar as for these variables. Among adults, in track and field, sprint athletes are taller, leaner and more muscular. Long-distance and middle-distance runners are shorter and have a low body fat. Throwers are larger and have a higher fat percentage $e^{1,5}$. Similar values for sprinters, jumpers and endurance runners have also been found in other studies ${ }^{1,5,15}$. For these groups, characteristics such as presence of low fat mass and predominance of lean mass were well evidenced in the athletes. The fact that throwers have a greater body mass does not negatively interfere with performance; on the contrary, this characteristic favors these athletes in their performance ${ }^{1}$. However, studies that analyze the relationship between body composition and performance suggest that the result is more related to muscle strength and power than simply to an increased lean mass ${ }^{16}$.

Flexibility, although considered one of the important physical valences for the practice of some track and field events, especially those that require the transposition of an object (barrier, obstacle, batten) ${ }^{17}$, there is no consensus in the literature on its importance for medium- and longdistance events. Beaudoin and Whatley Blum ${ }^{18}$ found a positive relation between greater flexibility in young athletes and better running economy. On the other hand, Craib et al. ${ }^{19}$ and Trehearn and Buresh ${ }^{20}$ found that, in athletes of these events, runners with lower levels of flexibility tend to be more economical than those who are more flexible. This may favor its performance by having a lower level of flexibility. Thus, further studies on flexibility and performance should be performed to realize the true value of this variable for the result in track and field events. Our results show that all groups have a high level of flexibility, which, according to the literature, does not prove to be an obstacle to track and field. No significant differences were found. Therefore, it would not be a variable that could be used 
to identify the greater potential for a given group of events.

The maximal aerobic velocity achieved in the Léger-Boucher continuous maximal test has been presented by trainers as an indirect and alternative measure of maximal oxygen consumption speed. It becomes even more important when, for example, $\mathrm{VO}_{2 \max }$ does not differentiate performance among subjects in a same group. Thus, the VMA is more accurate for this assessment. This variable is known to be one of the most important for success in long-distance and medium-distance races ${ }^{21}$. In the analysis by event group, significant differences were observed between endurance athletes and throwers and jumpers. In official U16 competitions, sprinters participate in events of up to $250 \mathrm{~m}$ and endurance athletes in events of up to $1,000 \mathrm{~m}$. These events are very similar, and their training in this age group is also similar. This may have influenced the similarity in VMA between speed and endurance runners.

The ability to produce muscle strength and power is essential for sports performance in a variety of modalities ${ }^{22}$. Therefore, several tests have been used to assess these physical abilities in order to predict sports performance, prescribe training sessions and monitor progress during a typical track and field training cycle ${ }^{23}$. Due to their timesaving and practical characteristics, vertical jumps are widely used to assess the lower limb explosive strength of high-level athlete ${ }^{24,25}$. To some extent, this can be explained by the high association values found between vertical jump measurements and a range of motor tasks in individual and team sports ${ }^{24,25}$. In track and field, in addition to their use as indicators of lower limb muscle strength, variables that include vertical jump can be used to differentiate power and endurance athletes ${ }^{26}$. These differences are possibly related to the characteristics of these types of athletes together with adaptations induced by the specific physiological demands of each event ${ }^{27}$. To evaluate the vertical impulse, in this study, we used the protocols of the Squat Jump and the CounterMovement Jump, and found superior results to those found by Mariano ${ }^{28}$ for normomature female athletes. No significant differences were found between groups, which shows that the variable alone should not be used to differentiate the potential for one of the event groups. For the assessment of upper limb strength, as there are still few tests that evaluate this variable specifically for track and field, we opted to use medicine ball throw because of the way it is executed, totally isolating the upper limbs and working the explosive force. The results obtained by the total group were classified as "very good" by the reference table of PROESP - BR ${ }^{29}$. No significant differences were found between the groups of events. In this case, this variable also does not differentiate the athlete's potential in different events.

To evaluate anaerobic performance, the RAST protocol was used to determine the accumulated fatigue index among stimuli for young track and field athletes. According to Paradisis ${ }^{30}$, the parameter determined has shown significant correlations with the max performances in $100 \mathrm{~m}, 200 \mathrm{~m}$ and $400 \mathrm{~m}$ adult runs. It can predict any performance changes and could be used as a training tool for anaerobic training. The athletes evaluated in 
this study obtained on average $19.0 \%$ of fatigue index, a value considered within normal when compared to other modalities. By analyzing this variable by event group, there were no significant differences between them. It is though important to evaluated such characteristics within the modality, as they are not sufficient to differentiate event groups.

In the set of tests related to specific skills, significant differences were found among the $60 \mathrm{~m}$ run, the shot put, and the $800 \mathrm{~m}$ run. The groups presented similar results only for long jump. The differences found occur predominantly in the group of throwers, who obtained lower results in the 60 and $800 \mathrm{~m}$ runs and higher in shot put. Such differences can be explained by their larger body dimensions, as well as by the technical characteristics that involve the training of shot put in relation to the others. Because of this skill set, it is possible to identify specificities in sports potential, differentiating the throwers from the other groups.

Despite reaching approximately $10 \%$ of the athletes regularly enrolled in the Brazilian Athletics Confederation, due to the characteristics of data collection, difficulty in logistics and the large territorial space in Brazil, the study sample only includes athletes from the southeastern region of the country.

Track and field coaches are recommended to use the proposed testing battery, as well as the reference values shown in mean/standard deviation and percentile tables in this study, in order to identify in the category under 16 the overall sporting potential of young athletes. This battery also monitors their development during the training process and in future competitive seasons. It is noteworthy that these reference values were obtained from a specific population of under 16 young female athletes.

Regarding the identification of potential by event group, it is possible to identify in the averages tables that the throwers deserve special attention. Throwers are larger, slower, and have a lower resistance. They also throw farther. They are statistically different from the others among the variables analyzed.

Regarding the use of the percentile table, it should be used to identify the sporting potential for track and field. The tests are very specific to the sport, and many coaches already use them in their athlete evaluation routines. Coaches can choose from the table which tests to apply and rank the results found in the percentile table. The higher the percentile value, the closer to the best athletes in the category under 16.

\section{CONCLUSION}

Considering the number of athletes evaluated and the tests applied, it was possible to construct the reference tables of mean and percentile for under 16 athletes. The classification should be done globally paying special attention to throwers who are larger, slower, have a lower endurance and throw weights farther. 


\section{COMPLIANCE WITH ETHICAL STANDARDS}

\section{Funding}

This research did not receive any specific grant from funding agencies in the public, commercial, or not-for-profit sectors. This study was funded by the authors.

\section{Ethical approval}

Ethical approval was obtained from the local Human Research Ethics Committee - University Federal Juiz de Fora and the protocol (no. 566.839) was written in accordance with the standards set by the Declaration of Helsinki.

\section{Conflict of interest statement}

The authors have no conflict of interests to declare.

\section{Author Contributions}

Conceived and designed the experiments: J.V.F, J.R.P.L, F.Z.W, A.J.F and P.H.C.C. Performed the experiments: J.V.F, R.S.S, J.R.P.L and P.H.C.C. Analyzed the data: J.V.F, F.Z.W and J.R.P.L. Contributed reagents/materials/analysis tools: V.F, J.R.P.L, A.J.F, F.Z.W and P.H.C.C. Wrote the paper: J.V.F, J.R.P.L, A.J.F, F.Z.W and P.H.C.C.

\section{REFERENCES}

1. O'Connor H, Olds T, Maughan RJ. Physique and performance for track and field events. J Sports Sci 2007;25 Suppl 1:S49-60.

2. Böhme M. Treinamento a longo prazo e o processo de detecção, seleção e promoção de talentos esportivos. Rev Bras Ciênc Esporte 2010; 21: 4-10.

3. Bergmann G, Bergmann M, Lorenzi T, Pinheiro ES, Garlipp DC, Moreira RB, et al. Pico de velocidade em estatura, massa corporal e gordura subcutânea de meninos e meninas dos 10 aos 14 anos de idade. Rev Bras Cineantropom Desempenho Hum 2007;9(4):333-338

4. Malina R, Bouchard C, Bar-Or O. Growth, Maturation and Physical Activity (2nd ed.). Champaign, IL: Human Kinetics, 2004; 215-233.

5. Hirsch KR, Smith-Ryan AE, Trexler ET, Roelofs EJ. Body Composition and Muscle Characteristics of Division I Track and Field Athletes. J Strength Cond Res 2016;30(5):1231-8.

6. The Internacional Society for Advancement for Kineanthropometry (ISAK). First printed. 360 Australia; National Library of Australia, 2001.

7. Zacharogiannis E, Paradisis G, Tziortzis S. An evaluation of tests of anaerobic power and capacity. Med Sci Sports Exerc 2004; 36(5):S116.

8. Wells KF, Dillon EK. The Sit and Reach-A Test of Back and Leg Flexibility. Res Q1952; 23(1):115-118.

9. Rodrigues M, Marins JC. Counter movement e squat jump: análise metodológica e dados normativos em atletas. Rev Bras Ciênc Mov 2012;19:108-119.

10. Gaya A, Lemos A, Gaya A, Teixeira D, Pinheiro E, Moreira R. Projeto Esporte Brasil PROESP-Br. Manual de Aplicação de Medidas e Testes, Normas e Critérios de Avaliação, 2012.

11. Léger L, Boucher R. An indirect continuous running multistage field test: the Université de Montréal track test. Can J Appl Sport Sci 1980; 5: 77-84. 
12. Kuipers H, Verstappen F, Keizer H, Geurten P, van Kranenburg G. Variability of Aerobic Performance in the Laboratory and Its Physiologic Correlates. Int J Sports Med 1985;6(4):197-201.

13. Khamis H, Roche A. Predicting adult stature without using skeletal age: the Khamis-Roche method. Pediatrics 1994; 94(1): 504-507.

14. Malina RM, Eisenmann JC, Cumming SP, Ribeiro B, Aroso J. Maturity-associated variation in the growth and functional capacities of youth football (soccer) players 13-15 years. Eur J Appl Physiol 2004;91(5-6):555-62.

15. Pipes TV. Body Composition Characteristics of Male and Female Track and Field Athletes. Res Q1977;48(1):244-7.

16. Terzis G, Kyriazis T, Karampatsos G, Georgiadis G. Muscle Strength, Body Composition, and Performance of an Elite Shot-Putter. Int J Sports Physiol Perform 2012;7(4):394-6.

17. Corbin C. Flexibility. Clin Sports Med 1984;3(1):101-17.

18. Beaudoin CM, Whatley Blum J. Flexibility and running economy in female collegiate track athletes. J Sports Med Phys Fitness 2005; 45: 295-300.

19. Craib MW, Mitchell VA, Fields KB, Cooper TR, Hopewell R, Morgan DW. The association between flexibility and running economy in sub-elite male distance runners. Med Sci Sports Exerc 1996;28(6):737-43.

20. Trehearn TL, Buresh RJ. Sit-and-Reach Flexibility and Running Economy of Men and Women Collegiate Distance Runners. J Strength Cond Res 2009;23(1):158-62.

21. Billat LV. Use of Blood Lactate Measurements for Prediction of Exercise Performance and for Control of Training. Sports Med 1996; 22: 157-175.

22. Cormie P, McGuigan MR, Newton RU. Developing Maximal Neuromuscular Power. Sports Med 2011; 41: 17-38.

23. Cronin JB, Hansen KT. Strength and Power Predictors of Sports Speed. J Strength Cond Res 2005;19(2):349-57.

24. Loturco I, D凶Angelo RA, Fernandes V, Gil S, Kobal R, Cal Abad CC, Kitamura K, Nakamura FY. Relationship between sprint ability and loaded/unloaded jump tests in elite sprinters. J Strength Cond Res 2015;29(3):758-64.

25. Köklü Y, Alemdaroğlu U, Özkan A, Koz M, Ersoz G. The relationship between sprint ability, agility and vertical jump performance in young soccer players. Science Sports 2015; 30: e1-e5.

26. Loturco I, Gil S, Laurino CF, Roschel H, Kobal R, Cal Abad CC, Nakamura FY. Differences in muscle mechanical properties between elite power and endurance athletes: a comparative study. J Strength Cond Res 2015;29(6):1723-8.

27. Kim H, Song K-H, Kim C-H. The ACTN3 R577X variant in sprint and strength performance. J Exerc Nutrition Biochem 2014;18(4):347-53.

28. Mariano T, Arruda M, Pascoal EHF, Lazari E, Muniz Y. Jovens praticantes de atletismo: contribuição da maturação e variáveis antropométricas no desenvolvimento da força explosiva e velocidade em púberes e pós-púberes durante cinco meses de treinamento. Conexões 2011; 9: 92-108.

29. Gaya A, Silva G. Manual de aplicação de medidas e testes, normas e critérios de avaliação. Projeto Esporte Brasil, 2007; 1-27.

30. Paradisis GP, Tziortzis S, Zacharogiannis E, Smirniotou A, Karatzanos L. Correlation of the running-based anaerobic sprint test (RAST) and performance on the $100 \mathrm{~m}, 200 \mathrm{~m}$ and 400m distance tests. J Hum Mov Stud 2005; 49: 77-92.

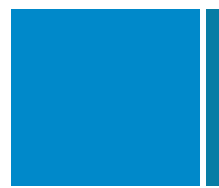

Corresponding author

Jefferson Verbena de Freitas

Rua Vereador Tarcísio Cordeiro Gomes, n 80, bairro Várzea, Tocantins-MG.

Brasil, CEP: 36512-000

E-mail: jeffersonverbena@gmail.com 